\title{
A Neighborhood View of Interactions among Individual Plants
}

\author{
Peter Stoll and Jacob Weiner
}

\subsection{Introduction}

In no area of ecology is the role of space more fundamental than in the study of plant communities (Hutchings 1986; Crawley and May 1987). Individual plants are rooted in one place and their ability to move and occupy space is restricted to growth (Eriksson 1986). A plant cannot relocate from an unfavorable location to a more favorable one. Rather, it grows as well as possible where it finds itself or it dies. Basic plant biology suggests that plant-plant interactions are inherently local in nature. For example, individual plants do not experience global population density per se, but only interact with neighbors over restricted distances. The mobility of animals makes their spatial behavior potentially far more complex than that of plants, but, ironically, this ability to move can make the modeling of space for animal populations unnecessary in many cases. For example, because animals can "diffuse" in space from areas of higher density to areas of lower density, models based on mean spatial behavior or overall density may often be sufficient. Because a plant's ability to move is quite restricted (except during dispersal), local conditions are of much greater significance to plants than to animals. When feeding fish in a tank, it does not matter where on the water surface one places the food, because the fish will come to it. But when watering or fertilizing the garden one must make sure that the resource comes close to the plant - if one waters only half the garden the other half will not obtain sufficient water. Thus, while it is possible that the spatially averaged behavior of individuals may sometimes provide sufficient information for modeling some processes within populations and communities, this is much less likely to be the case for plants than for animals. 


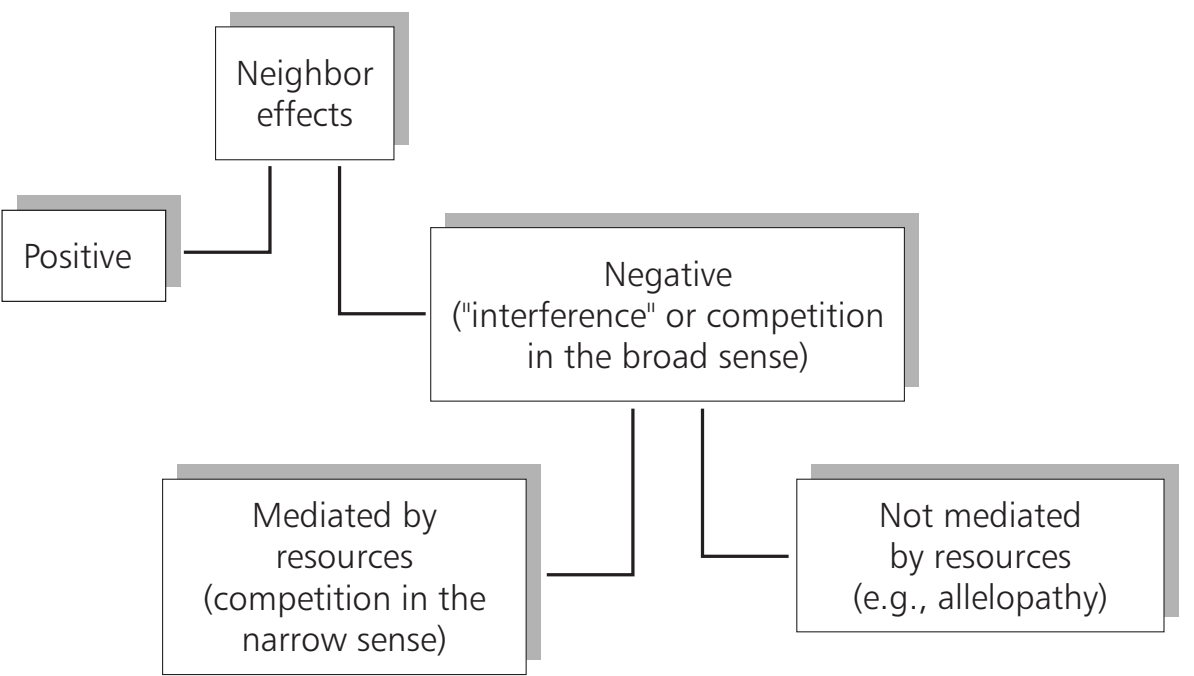

Figure 2.1 Classification of neighbor effects in plants.

In this chapter, we discuss the role of local spatial processes in plant communities, focusing on the concept of an individual's neighborhood. We emphasize competition among plants because it is thought to be one of the primary factors determining plant performance in the field and has therefore been the most studied ecological interaction in plant communities. However, the neighborhood approach taken here could also be applied to other ecological interactions, such as herbivory or pollination. Our goal in the context of the present volume is to foster much-needed communication between theoreticians and empiricists in ecology by providing modelers with an empirical perspective on local plant interactions, which we hope will be of use in building models and developing modeling techniques.

\subsection{Competition Mechanisms}

The study of interactions among plants in natural communities presents the ecological researcher with daunting complexity. The mechanisms by which plants interact are understood only at a general nonquantitative level (Bazzaz 1990), although we can be encouraged by a few robust patterns at the population level, such as the relationship between density and biomass (Silvertown and Lovett Doust 1993). In discussing interactions among plants, our conceptual framework follows that of Harper (1977). Plants are influenced by neighbors, and we call all such interactions "neighbor effects" (Figure 2.1). While many of these effects are negative ("interference" sensu Harper or competition in the broad sense), some are positive. Positive neighbor effects, such as protecting neighbors from excessive solar radiation and resultant water loss and providing mechanical support and 
Box 2.1 Positive neighbor effects

Plants can have positive as well as negative effects on their neighbors. The classic example of positive neighbor effects is that of "nurse plants" in arid systems (e.g., Franco Pizana et al. 1996). Some desert plants can only establish themselves in close proximity to a larger plant, usually a shrub, because the shade of the larger plant provides protection from the intense solar radiation and resultant heat and transpiration that a seedling otherwise would experience. Plant establishment in deserts is largely determined by the negative effects of a superabundant plant resource - solar radiation for which plants in other environments compete. There has been increased interest in positive plant-plant interactions. Below are two examples.

During drought periods, sugar maple (Acer saccharum) demonstrates "hydraulic lift," nocturnal uptake of water by roots from deep soil layers that is released from shallow roots into upper soil layers (Dawson 1993). Neighboring plants use from 3-60\% of the hydraulically lifted water supplied by sugar maple trees. Hydraulic lift may not be limited to arid or semiarid environments where chronic water deficits prevail and might be important in relatively mesic environments when subjected to periodic soil water deficits.

Facilitation by neighbors may be quite common in wetlands. For example, emergent wetland plants often alleviate the effects of anaerobic soils on root respiration by transporting oxygen below-ground through continuous air spaces (aerenchyma) within the plant. Oxygen leaking from the roots into the rhizosphere may oxidize minerals in the soil or become available to other plants. Callaway and King (1996) investigated the ability of cattail (Typha latifolia), a widespread wetland plant with aerenchymous tissue, to aerate sediments and affect the growth of two neighbors, a willow (Salix exigua) and forget-me-not (Myosotis laxa). At lower temperatures, rooted willow cuttings survived only when planted with cattail and forget-me-not transplants grew significantly larger when planted with cattail. At higher soil temperatures, however, there was evidence of competition rather than facilitation.

protection from herbivores, may be more common than previously thought (Box 2.1; Aarssen and Epp 1990). In some ecosystems, particularly those of nutrient-poor or other extreme environments such as salt marshes (e.g., Bertness and Shumway 1993), positive effects may be as important as negative effects. It is important to remember that the net effect of one plant on another is the sum of positive and negative effects (Berkowitz et al. 1995). Because the relative importance, timing, and spatial structure of the numerous positive and negative mechanisms may vary, it is not easy to summarize 
the effects plants have on one another by using simple coefficients. Chapter 3 gives an overview of how plant ecologists have tried to obtain this information and the results accumulated so far.

Negative neighbor effects are usually more important than positive ones, because all plants require basically the same resources. If plants are growing in close proximity, it seems almost inevitable that they will eventually compete for some of these resources. Negative neighbor effects can be divided into those mediated by resources (competition in the narrow sense) and those mediated by other mechanisms or organisms (Figure 2.1). Indirect neighbor effects include changes in environmental conditions such as temperature, humidity, and wind velocity, and attraction or repelling of animals, which thereby affects predation, trampling, etc. (Harper 1977). Most plant ecologists consider competition for resources to be generally more important and more likely to be predictable than other neighbor effects, but there may be communities in which other mechanisms such as allelopathy play a major role (Rice 1984). Quantifying mechanisms such as allelopathy in a field situation is a distant goal, but ecologists have begun to study resource-mediated competition quantitatively (Tilman 1982, 1988; Fitter 1986; Keddy 1991).

It is important to distinguish between the effects an individual plant has on resources and how that plant responds to the preemption of resources by its neighbors (Goldberg 1990; Tremmel and Bazzaz 1993). Thus, the intensity of competition is determined by two processes: (1) the effects of neighbors on resource availability and (2) the ability of individuals to tolerate or compensate for these effects through plasticity and other "behavioral" responses (Box 2.2). Plasticity is the ability of a single genotype to develop into different phenotypes in different environments (Bradshaw 1965). For example, plants can change their growth form in response to neighbors - for instance, by putting more effort into height growth at the expense of lateral growth when they are shaded (Schmitt 1993; Schmitt and Wulff 1993) or can "expect" to be shaded in the near future (Ballaré et al. 1990). Resource acquisition depends on the placement of plant parts in relation to resources and the ability to take up these resources when they are encountered. The ways plants obtain resources, use them to obtain more resources, and consequently make these resources unavailable to neighboring plants, and the ways plants respond to reduced resource levels caused by neighbors can be considered the mechanisms of resource competition (Bazzaz 1990). The effects of plants on each other in the field are primarily the result of such mechanisms. 
Box 2.2 Plant behavior: Clonal growth, foraging, and division of labor

Higher plants are composed of a repetitive branched system of units (e.g., ramets, modules), each consisting of a segment of stem, leaves, and axillary buds (meristems) with the potential to form a new unit. The whole shoot system is a population of such units that may be united in sharing a common root system. This unity is often lost during clonal growth lateral spread by "vegetative reproduction" - of plants such as strawberries (Figure 2.2). When connecting horizontal parts of the shoot systems (stolons or rhizomes) die and rot away, rooted, physiologically independent offspring are left (Harper 1977). One consequence of the modular construction of plants is that leaves and root tips are located on branches that project them into habitat space (Bell 1984; Schmid 1990; Hutchings and de Kroon 1994). The architecture of resulting branching patterns can be described by variables such as spacer length, branching frequency, and branching angles. Morphological plasticity refers to changes in these architectural parameters in response to the plant's environment.

In an analogy to foraging in animals, Slade and Hutchings (1987a) defined "foraging" in plants as "the process whereby an organism searches or ramifies within its habitat in the activity of acquiring essential resources." According to this analogy, leaves and root tips (resource-acquiring structures) are "feeding sites," which are located at the ends of "spacers" (i.e., horizontal branches). Shortening spacers and increasing branching in response to high local abundance of resources in order to place more feeding sites into resource-rich microhabitats should increase resource acquisition from the habitat and enhance plant fitness (Hutchings 1988).

Spacers not only place feeding sites within the environment, they also perform bidirectional transport processes, thus providing intraclonal specialization and cooperation analogous to the economic principle of spatial division of labor between shoots in different patches within the environment (Stuefer et al. 1994; Stuefer 1995). Water provided through stolons from shoots growing in shaded microhabitats may be delivered to shoots growing in full sunlight, while shoots in full sunlight may provide assimilates to shoots growing in areas with lower light levels (Evans 1991, 1992).

Simply put, resource-mediated competition occurs when individual plants consume resources which are therefore not available to other individuals. If the lack of a resource limits the growth of an individual, then that individual has suffered from competition. One important difference between plants and animals is that animals of different species may have varying degrees of overlap in the resources they need. In some cases, two different animal species may use few, if any, of the same resources. Plants, 


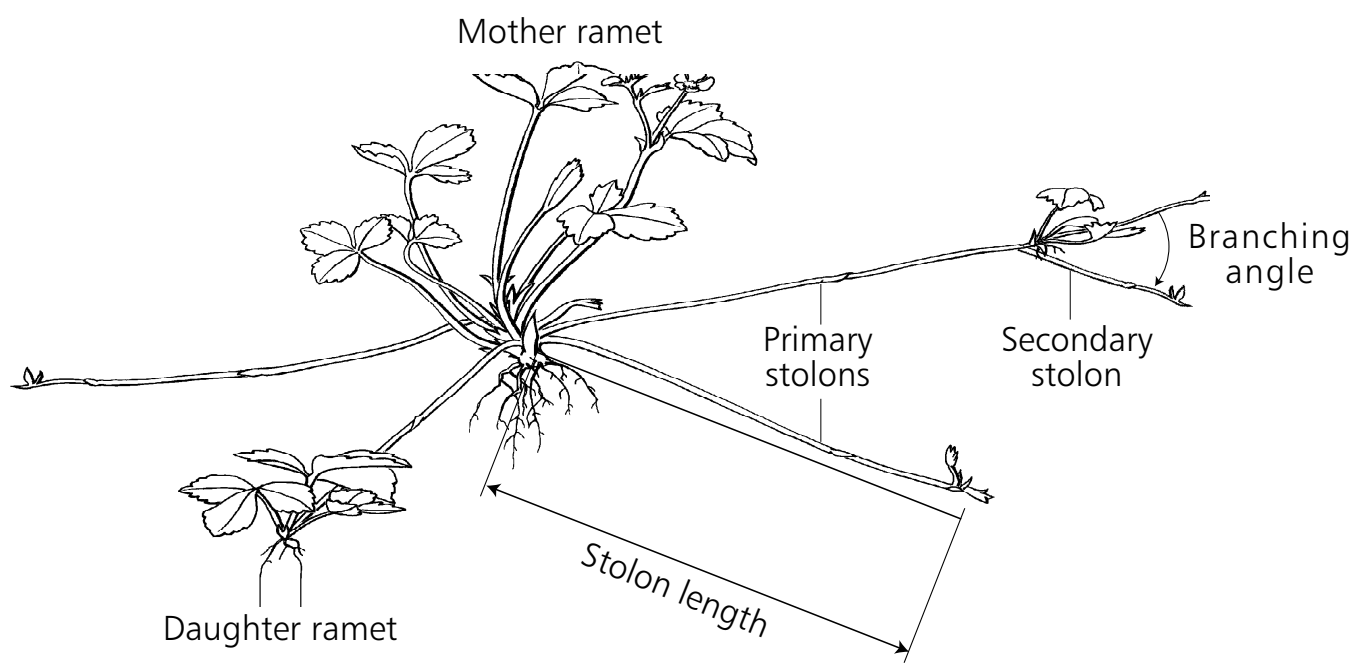

Figure 2.2 A strawberry (Fragaria sp.) as an example of clonal growth. The genetic individual ("genet") consists of numerous physiological/morphological individuals ("ramets") that may exchange resources if they remain connected or live independently if connections (stolons, i.e., horizontal shoots) are no longer functional. Clonal growth by plants can be seen as analogous to movement by animals.

on the other hand, all need the same basic resources: physical space, light, carbon dioxide, water, oxygen, and a suite of mineral nutrients. Thus, the ability of plants to avoid competition through niche differentiation is quite limited, although plants can use resources in different proportions (Tilman 1982), at different depths in the soil (Parrish and Bazzaz 1976, 1985), or at different times of the year (Eissenstat and Caldwell 1988).

Ecologists have begun to develop general models for local depletion and renewal of soil resources (Fitter and Stickland 1991; Fitter et al. 1991; Huston and DeAngelis 1994; Leadley et al. 1997), but it is not clear how far such generalizations can take us. Light, for example, is so fundamentally different from other resources that it is difficult to imagine how it can be treated similarly to soil resources. Light is unidirectional, cannot be stored (although the products of photosynthesis can), and does not diffuse from one point in space to another. In this sense, light as an energy source is inherently local: a plant cannot benefit from light that it does not intercept. Moreover, because plant movements are so limited, a plant's ability to move to areas of greater light availability is very restricted, although one can consider plants to be "foraging" through their growth patterns (Slade and Hutchings 1987b).

Although mineral nutrients are not unidirectional or renewable in the same sense as solar radiation, the diffusion of nutrients through the soil appears to be extremely limited. For example, plant roots can deplete local 
Box 2.3 Competition at the microscale: Distribution and dynamics of neighboring plant roots

Although roots are difficult to observe, especially under field conditions, progress is being made. Caldwell and his coworkers (Caldwell et al. 1991, 1996) have used various techniques to investigate the deployment of roots in relation to neighboring plants and the availability of soil resources, which may vary both in space and time. For example, they found that root proliferation of the sagebrush (Artemisia) was considerably influenced by the presence of different grass species (Agropyron or Pseudoregneria). Root density of the shrub was generally two to three times higher with Pseudoregneria than with Agropyron, and there was a greater tendency for the roots of the shrub and Pseudoregneria to segregate (i.e., to avoid one another). Caldwell et al. (1991) interpreted these patterns as interference at the level of individual roots but only speculated about the possible mechanisms, such as resource pre-emption or allelopathy. In a subsequent experiment, Caldwell et al. (1996) found that shrub and grass roots tended to avoid each other at a scale of millimeters to centimeters, although there was no direct evidence of resource competition. While resource competition cannot be entirely dismissed, other mechanisms may have contributed to the species-specific relationships between shrub and grass roots. Growth inhibition of roots following contact with roots of other plants has been shown (Mahall and Callaway 1992; Krannitz and Caldwell 1995; Huber-Sannwald et al. 1996), and Caldwell et al. (1996) conclude that such species-specific and sometimes even genotype-specific responses strongly suggest a recognition mechanism.

nitrogen, which can diffuse from areas where it has not been depleted, but this occurs over very short distances and at the local level of neighboring fine roots (Box 2.3). Water is perhaps the most diffusible of plant resources, but the distances involved are still quite limited relative to the size of the plant. For example, in an experiment where water was supplied only to the outer root system (more than $10 \mathrm{~cm}$ from the center) of branch units of bunchgrass (Bouteloua gracilis) in containers, growth was significantly less than when water was applied only to the central root system (Hook and Lauenroth 1994).

Dispersal is one way that plants "move" extensively, and seeds can sometimes move great distances via wind and water, or with the help of animals. One function of dispersal may be to escape local competition. However, most studies show that, by far, most seeds end up very close to the mother plant. Seed dispersal can be modeled as a diffusion process, 
with fewer and fewer seeds at increasing distances from the plant (e.g., Pacala et al. 1996). Although long-distance dispersal is quite rare, it may be extremely important for plant community dynamics. Plant species diversity, for example, may often be limited by dispersal (Ricklefs and Schluter 1993; Tilman 1997). The few seeds that are dispersed far from their mother plant - that is, those that escape from the maternal plant's neighborhood may be able to escape mortality due to seed predators (Janzen 1970) or diseases (Augspurger 1984) concentrated near the mother plant. We can think of plants interacting at a local scale as they survive and grow, and subsequently experiencing a more mobile phase during propagule dispersal.

\subsection{Moving from the Population to the Individual Level}

Because of the local nature of plant interactions, analysis and modeling of plant-plant interactions have moved from "mean-field approximations" toward explicit modeling of local interactions. Until the mid-1980s the study of density dependence focused on mean plant behavior (Bleasdale and Nelder 1960; Watkinson 1980; Vandermeer 1984). However, there has been an increase in the study of what one could call local density dependence, that is, the study of the performance of individual plants as a function of their local competitive conditions. As is often the case in ecology, models of local competition have been less successful in accounting for variation in the observed phenomena in the field than in stimulating new ideas and approaches to the study of plant-plant interactions, and more questions have been raised than have been answered. It has been demonstrated that

- plants do interact locally;

- local crowding reduces plant growth, reproductive output, and probability of survival;

- the effect of neighbors attenuates with distance (although the nature of this attenuation is not well understood);

- beyond a certain distance plants have no detectable effect on each other.

For example, Tyler and D'Antonio (1995) showed that, for seedlings of the shrub Ceanothus impressus, both survivorship and growth increased with increasing distance from near neighbors. Their study site was a burned area, and disturbances such as fire might preclude competition by releasing a flush of nutrients or by reducing biomass and thereby diminishing the consumption of resources. Thus, even after disturbance, when some resources are apparently abundant on a large scale, competition for resources may be important in determining small-scale patterns of seedling growth 
and survival. Survival of seedlings was reduced by the presence of neighbors up to a distance of $20 \mathrm{~cm}$. More distant neighbors no longer had an effect on survival but still reduced growth. There are numerous studies that demonstrate negative neighborhood interactions (see Chapter 3). However, information on the relative importance of different mechanisms in different environments and evidence for the importance of the observed effects for population or community processes are rarely available.

\subsection{What is a Plant's Neighborhood?}

The study of local interactions begins with the question of what "local" means. We define a competitive neighborhood as an area within which a plant can be affected by local factors, such as the abundance of neighboring plants. There are two different approaches to the definition of a neighborhood. In one approach the neighborhood is defined as a patch of space within which plants interact. Interactions do not occur between patches, and all individuals within a patch can potentially interact. This framework comes from the study of environmental heterogeneity and has been further developed in the context of patch dynamics (Pickett and White 1985). Although such an approach has the virtue of simplicity, most plant ecologists find it insufficient to capture the spatial dynamics of plants. In contrast, a "plant-centered" view of neighborhoods does not aggregate all individuals within a patch of space but lets the individual define the neighborhood, usually thought of as a circular area around the individual. The study of local interactions among plants has moved in the direction of plant-centered neighborhoods.

In an ecological perspective that emphasizes plants' local neighborhoods, a major goal would be to describe the performance of a plant (its growth and reproductive output) as a function of the plant's genotype and local environment, broadly defined to include neighboring plants and other organisms. We are far from being able to describe such a function. In many studies, environmental heterogeneity, such as local variation in soil quality (Lechowicz and Bell 1991), seems to be more important than the local abundance of competing plants (Mitchell-Olds 1987). The question for modelers becomes, What would be an adequate description of a plant's neighborhood for a specific ecological purpose or research problem?

In the simplest plant-centered neighborhood approach, a neighborhood is defined by a radius from an individual plant's center, and the number of neighbors of different species within the area defined by the neighborhood radius is a measure of the local density. This approach has been extensively 
developed by Pacala, Silander, and their coworkers. Starting with populations of a single species of annual plant (Pacala and Silander 1985; Silander and Pacala 1985), they progressed to two-species models (Pacala 1986, 1987; Pacala and Silander 1987) that were fitted to field data (Pacala and Silander 1990). Predictors of individual plant performance, such as survival, growth, and reproduction, are functions of the number of neighbors in the neighborhood - a circular area around a subject plant circumscribing all other individuals that interact with the subject plant. In Pacala and Silander's models, the positions and sizes of neighbors within the neighborhood are not considered. They argue that when the "optimal" neighborhood size (i.e., the neighborhood radius of the circle that explains most of the variability in performance) was determined by statistical fitting, the number of neighbors within the neighborhood alone had almost equal predictive power as more detailed and complicated models. The assumptions of this approach are that the neighborhood can be considered internally homogeneous and that individuals of the same species can be considered equal, independent of their size. If these assumptions hold, then modeling and analyses of plant neighborhoods are quite tractable. In apparent contradiction to the emphasis on spatial dynamics in the recent literature (Durrett and Levin 1994b; Pacala and Deutschman 1995) and in this book, Pacala and Silander's model collapses into a mean-field model (Pacala and Silander 1990). This may be due to the fact that their local neighborhood model differs only in scale (local) and location (plant-centered) from meanfield models of density dependence ( $\mathrm{S}$. Thomas, personal communication). Pacala and Silander's local density model is just that: neighborhoods are defined around individuals and the local density (in the simplest sense, the number of individuals) is the independent variable.

Neighborhood competition studies have been criticized recently for several reasons. First, some researchers have questioned the implicit assumption that competition among nearby individuals is the primary determinant of observed dynamics. For example, Ellison et al. (1994) cite theoretical and experimental evidence showing that intrinsic variation in plant growth rate alone can give rise to hierarchical distributions of biomass or other metrics of plant size. Second, the statistical analysis of local competition is fraught with problems. For example, in most spatial models of plant population dynamics, plants are represented by mathematical points in space that occupy no area. For rosette-forming plants like Arabidopsis, individuals with a large diameter will necessarily have fewer neighbors than those 
with a small diameter when plants are considered as points and neighborhoods are defined by a fixed radius. A plant with a tight rosette of leaves at its base cannot have a neighbor above ground within the radius of the rosette itself. Thus, it is then unclear whether a particular individual is small because it has many neighbors or has many neighbors because it is small. This can be seen as another example of the general problem that it is usually inappropriate to look at plant performance (e.g., size) at time $t$ as a function of neighborhood conditions at time $t$ because these two quantities are not statistically or inferentially independent. Rather, we should take a dynamic perspective and try to look at performance over the period $t$ to $t+\Delta t$ as a function of neighbor conditions at time $t$. By including appropriate controls and alternative hypotheses in replicating Silander and Pacala's (1985) experiment with Arabidopsis, Ellison et al. (1994) concluded that neighborhood competition significantly affects population dynamics in plant monocultures because neighbors impair target plants' biomass, growth, and fecundity (relative to plants grown in the absence of competition). However, in addition to the expected effects on fecundity mediated by biomass, there were also neighbor effects on plant fecundity that were independent of the effects on plant shape and biomass. This suggests that we cannot always infer fecundity from plant size alone, which presents more obstacles to the development of neighborhood models of plant performance.

Because of the indeterminate, modular nature of plant growth and the resultant plasticity in plant size, which means that a neighbor may be a tiny seedling or a huge adult, many researchers consider the number of neighbors alone an insufficient measure of local crowding. Therefore, several researchers have attempted to describe the competitive neighborhoods of plants more fully by looking at the distance and size as well as the number and species of neighbors. Some researchers have adopted a more complete physical Ansatz to describing a plant's neighborhood: the effect of a neighbor is proportional to its size and decreases with the square of its distance from the subject plant (Weiner 1984). In such models different species can still have different per-unit-biomass effects through the use of competition coefficients. The amount of variation in individual plant performance that such models can "explain" ranges from nearly $0 \%$ to almost $90 \%$, depending on the model, the species, and the environment (Bonan 1993; Hara and Wyszomirski 1994). The amount of variation accounted for is usually quite low, possibly due to other factors such as genetic variation and microsite heterogeneity. For example, from 75 neighborhood analyses in 20 manuscripts Bonan (1993) derived an average of $42 \% \pm 28 \%$ (mean \pm s.d.) 

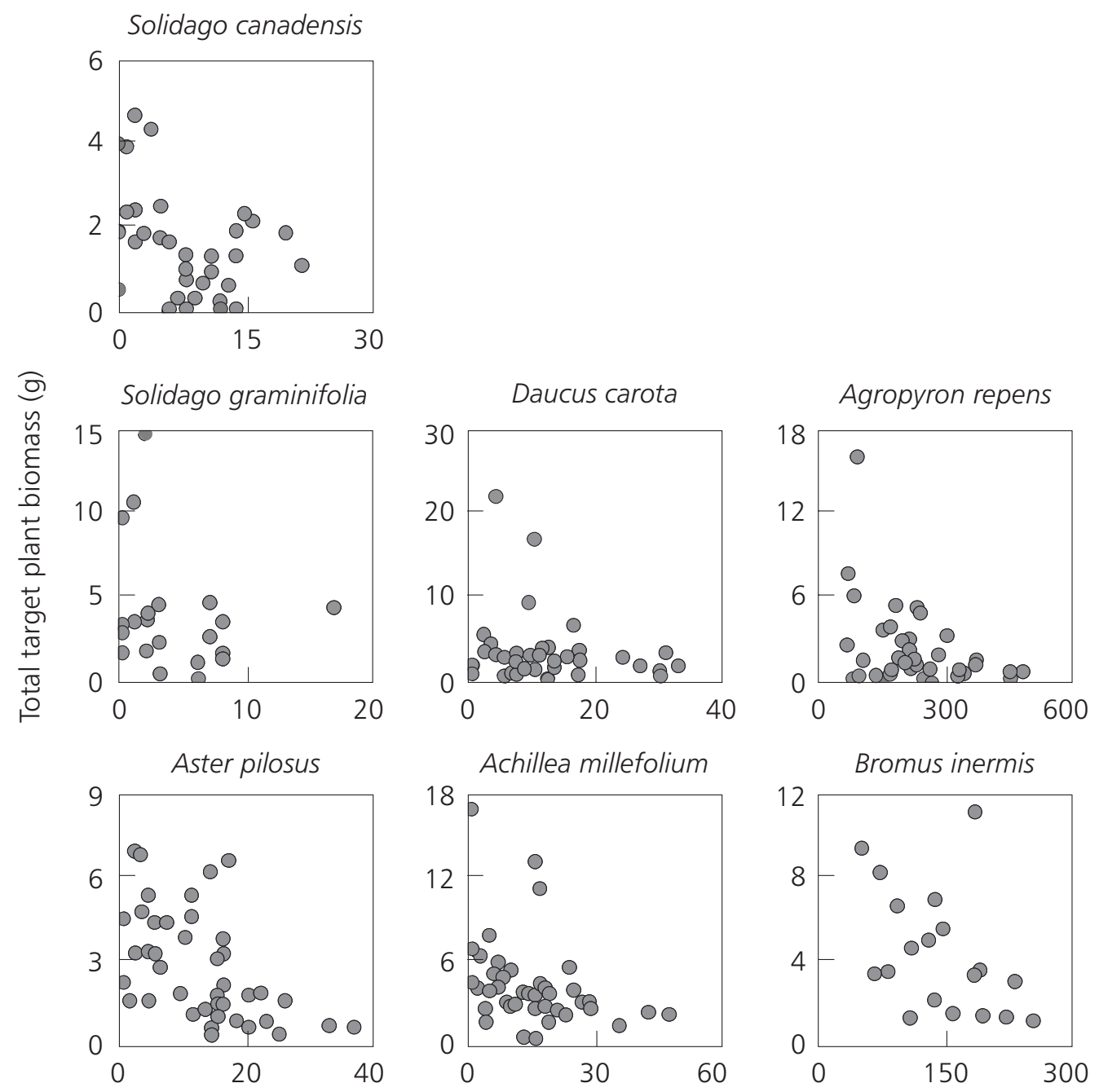

Total neighbor density (individuals/plot)

Figure 2.3 Biomass of target Solidago canadensis individuals versus local density for several species of neighbors. Source: Goldberg (1987).

of accounted-for variation. Sixty percent of these analyses accounted for less than half of the total variation in individual plant performance. These figures roughly correspond to an effect size of competition of $34 \% \pm 5 \%$ (mean $\pm 95 \%$ confidence interval) given for producers in a meta-analysis of 73 studies (Gurevitch et al. 1992).

The relationship between plant performance (e.g., growth or size) and the abundance of neighbors is often triangular (see Figure 2.3), suggesting that local competition is more a limiting condition than a direct determinant of plant performance. When neighbors are very abundant, plants will be small; but when neighbors are scarce, plants can be either large or small. This type of relationship suggests that either our measures of local competition are inadequate or local competition is just one of many factors 
determining individual plant performance. When local crowding is severe, it limits plant growth; but when local crowding is not so severe, plant growth is often limited by other factors in the local environment, such as soil quality or water availability.

Because plant growth is indeterminate and modular, leading to huge plasticity in plant size, and because all plants have basically the same requirements, several researchers have proposed that the size or biomass of neighbors is perhaps more important than their number or species. Size is thought to be an important determinant of competitive ability (Keddy and Shipley 1989). If neighbor size is important, equal per-unit-biomass effects of neighbors is the appropriate null model for comparing the effects of different species of neighbors on a target species (Goldberg and Werner 1983). Of course, different species may have different per-unit-size effects, but the size of a neighbor may be the single most important factor determining its effect on another plant. Although some researchers think that an emphasis on the size of neighbors rather than their species may be a useful first approximation for describing and modeling neighborhoods (whereas other researchers think this would be "throwing out the baby with the bathwater"), even modeling size effects alone is not as straightforward as it might seem at first. The relative size of neighbors with respect to a target plant is often as important as their absolute size, because competition among plants is usually "size asymmetric," that is, larger plants have a disproportionate (for their relative size) effect on smaller plants. The inclusion of size asymmetry can result in a marked improvement in the performance of neighborhood models of competition (Thomas and Weiner 1989).

Recent work in forest ecosystems (Pacala et al. 1996) demonstrates how useful a neighborhood approach can be when combined with mechanistic models of resource competition, as long as a balance between the level of detail and generality can be found that meets the basic design criteria of simplicity, observability, and biological realism. However, this balance can only be found if field methods, statistical estimators, and model structure are designed simultaneously to ensure that parameters can be estimated from data collected in the field (Pacala et al. 1996). Many plant ecologists believe that such mechanistic neighborhood models are much more promising than earlier, purely phenomenological models. 


\subsection{Challenges for a Neighborhood Perspective of Plant Interactions}

Another problem in developing a neighborhood-based view of plant-plant interactions is that the location of an individual, and often the individual itself, usually is not easy to define. In certain cases where plants have an erect main stem, an individual's location can be adequately described as a point in two-dimensional space (Stoll et al. 1994). However, many plants do not have such a straightforward location or identity. Plants are often clonal (Figure 2.2; Box 2.2; see Chapters 3 and 4) and it is their open, "modular" architecture (Schmid 1990) that enables them to respond to their local environment by "adjusting" birth, growth, and death of modules (Box 2.4). The modules (also called ramets if they are capable of living on their own) can remain connected through horizontal structures, and the extent and importance of transport processes and possible sharing of resources among modules are much debated in the literature. However, in contrast to modules such as branches of trees, the ramets of clonal plants are also capable of living independently when the connections become severed; indeed, in many clonal plants the loss of connections after ramets have been placed and established seems to be the rule. Thus, clonal plants (and to some degree non-clonal plants) have a hierarchical structure in which the genetic individual (genet) is made up of smaller physiological units (ramets).

In the field it is usually quite difficult, if not impossible, to identify genets: what we see are ramets. In a ramet-based neighborhood view, many of an "individual's" neighbors may be (genetically) the individual itself. Severe competition among genetically identical individuals decreases Darwinian fitness. From a sociobiological viewpoint, one can ask if individuals are able to recognize "themselves," and there is evidence that plant roots react differently to contact with genetically identical roots than to roots of other genets (Huber-Sannwald et al. 1996). It could be that such recognition is quite limited, in which case we could build hierarchical neighborhood models with genets growing by iterating and placing ramets that maintain their connections for a given amount of time or under given conditions (Bell 1986). In fact, clonal growth can make the description of growth easier to the extent that we can describe size simply as the number of ramets, either considering all ramets equal or having just a few size classes. The modeling of clonal growth can benefit from a neighborhood perspective (e.g., Cain et al. 1995). For example, most models of clonal spread are based on simple rules for internode length, branching frequency, and branching angle, and these parameters are assumed to apply to a whole 
Box 2.4 Demography of plant parts and neighborhood interactions below the individual scale

It has been shown that modules of trees, like ramets of herbaceous plants, respond to their local environment (Jones 1985; Franco 1986; Jones and Harper 1987a, 1987b; Franco and Harper 1988). These studies used the demography of modules (see also Maillette 1982a, 1982b) to describe tree growth. The most comprehensive approach is to combine the study of allocation patterns with that of the demography of modules (Küppers 1994). It should be noted that even if modules within branches respond to their immediate local environment, branches within trees may still be integrated (Sprugel et al. 1991). For example, within shaded branches of trees that had some branches in full sunlight yearly growth increments were smaller than growth increments of branches of control trees growing completely in the shade (Stoll and Schmid 1998). This difference was interpreted as correlative inhibition, for example, resource allocation to branches in the sun that therefore inhibited the growth of shaded branches. Evidence for such an interpretation was demonstrated in pea plants (Pisum sativum) by Novoplansky et al. (1989). When they grew two connected shoots in different light conditions, the shaded shoot was inhibited and eventually even withered and died. It elongated and became etiolated only when the shoot in the stronger light was removed.

We know of only one model of plant competition that explicitly includes plasticity at a modular level (Sorrensen-Cothern et al. 1993). Including plasticity through modular foliage in their spatially explicit model of competition fundamentally changed the population structure. For example, if trees were equipped with plasticity through modular foliage, the whole stand had a greater leaf area index and individuals grew taller than without plasticity.

genet (Sutherland and Stillman 1988). A more recent view is that the general rules are not completely fixed for an individual, but vary locally in response to local conditions. A parallel can be drawn between the growth of individual plants responding locally to the environment and foraging animals (Hutchings and de Kroon 1994). The point here is simply that even if the individual plants we see above ground are genetically and sometimes physiologically parts of larger organisms, behavior can, to some degree, be explained by local neighborhood conditions. The definition of an individual and of its neighborhood is best determined in the context of the scientific question being asked.

The difficulties of spatially delimiting plant neighborhoods are made much worse because the size of a plant increases by many orders of 
magnitude during its growth from a seedling to a reproducing adult. Thus, we would expect the area in which a plant experiences and is experienced by neighbors to increase accordingly. Most neighborhood studies investigate plant performance over one time interval with one neighborhood definition. It is difficult for many field ecologists to imagine such an approach yielding sufficient information to enable us to predict the dynamics of the system. In many cases, it may be necessary to model plant growth over several intervals during which the neighborhood grows along with the plant. Therefore, we predict better performance of future models with dynamic neighborhoods as opposed to the a priori fixed neighborhoods used in cellular automata.

\subsection{Suggestions for Modelers}

We have taken an empirical approach in an attempt to communicate to theoreticians some of what we empiricists think are the essential aspects and central questions in the development of a neighborhood approach to interactions among plants. There has been an increasing emphasis on bridging the gap between modeling and empirical work in ecology, although the tendency for the two to go in totally different directions is still very strong (Weiner 1995). In the spirit of building this much-needed bridge, we make the following suggestions to our theory-oriented colleagues.

- Models are more likely to be useful in solving empirical problems if they are directed at observed patterns in nature rather than at very general, abstract questions (Grimm 1994; Weiner 1995).

- Each model should have a clear purpose. The model should not be the object of study, but merely a tool. If the "occupational hazard" of being a field ecologist is thinking that everything is important and therefore must be included, the occupational hazard of theoreticians is building general, abstract models without a clear goal other than exploring the dynamics of the model itself. The question of how to simplify the model (or, in other words, how to determine what can be ignored) is closely linked to the model's goal. If the purpose of a model is to predict community dynamics (i.e., the abundance of different species over time), then what is essential for the model may be very different from what is essential in a model concerning persistence (how many species can coexist, independent of their specific abundances) or the genetic diversity of some species.

Perhaps the most important potential role for modeling in ecology today could be to help direct empirical research. At this point in the development 
of ecology, models may be most useful not for what they can deliver in the near future in terms of prediction, but for elucidating the sorts of information that are most needed if we are to build models that can do what we want them to do. Models can help make empirical research more strategic and less haphazard. If a formal, systematic theoretical framework can serve as an alternative to trial and error in exploring empirical "parameter space," advances in mathematical theory will have contributed much to what future generations of scientists will (we hope) call the emergence of a mechanistic and predictive ecology.

Acknowledgments We wish to thank E. Schreier for drawing Figure 2.2, and D.E. Goldberg and the Ecological Society of America for permission to use Figure 2.3. J.R. Porter and D. Newbery made valuable comments on an earlier version of the manuscript. This work was financially supported by grants from the Swiss National Science Foundation and the Roche Research Foundation. 


\section{References}

References in the book in which this chapter is published are integrated in a single list, which appears on pp. 517-552. For the purpose of this reprint, references cited in the chapter have been assembled below.

Aarssen LW \& Epp GA (1990). Neighbor manipulations in natural vegetation: A review. Journal of Vegetation Science 1:13-30

Augspurger CK (1984). Pathogen mortality of tropical tree seedlings: Experimental studies of the effects of dispersal distance, seedling density, and light conditions. Oecologia 61:211-217

Ballaré CL, Scopel AL \& Sanchez RA (1990). Far-red radiation reflected from adjacent leaves: An early signal of competition in plant canopies. Science 247:329-332

Bazzaz FA (1990). Plant-plant interactions in successional environments. In Perspectives on Plant Competition, eds. Grace JB \& Tilman D, pp. 239-263. San Diego, CA, USA: Academic Press

Bell AD (1984). Dynamic morphology: A contribution to plant population ecology. In Perspectives on Plant Population Ecology, eds. Dirzo R \& Sarukhan J, pp. 48-65. Sunderland, MA, USA: Sinauer Associates

Bell AD (1986). The simulation of branching patterns in modular organism. Philosophical Transactions of the Royal Society of London B 313:143-159

Berkowitz AR, Canham CD \& Kelly VR (1995). Competition versus facilitation of tree seedling growth and survival in early successional communities. Ecology 76:1156-1168

Bertness MD \& Shumway SW (1993). Competition and facilitation in marsh plants. The American Naturalist 124:718-724

Bleasdale JKA \& Nelder JA (1960). Plant population and crop yield. Nature 188:342

Bonan GB (1993). Analysis of neighborhood competition among annual plants: Implications of a plant growth model. Ecological Modelling 65:123-136

Bradshaw AD (1965). Evolutionary significance of phenotypic plasticity in plants. Advanced Genetics 13:115-155

Cain ML, Pacala SW, Silander JA Jr \& Fortin MJ (1995). Neighborhood models of clonal growth in the white clover Trifolium repens. The American Naturalist 145:888-917

Caldwell MM, Manwaring JH \& Durham SL (1991). The microscale distribution of neighboring plant roots in fertile soil microsites. Functional Ecology 5:765772

Caldwell MM, Manwaring JH \& Durham SL (1996). Species interactions at the level of fine roots in the field: Influence of soil nutrient heterogeneity and plant size. Oecologia 106:440-447

Callaway RM \& King L (1996). Temperature-driven variation in substrate oxygenation and the balance of competition and facilitation. Ecology 77:11891195 
Crawley MJ \& May RM (1987). Population dynamics and plant community structure: Competition between annuals and perennials. Journal of Theoretical Biology 125:475-489

Dawson TE (1993). Hydraulic lift and water use by plants: Implications for water balance, performance and plant-plant interactions. Oecologia 95:565-574

Durrett R \& Levin S (1994b). The importance of being discrete (and spatial). Theoretical Population Biology 46:363-394

Eissenstat DM \& Caldwell MM (1988). Seasonal timing of root growth in favorable microsites. Ecology 69:870-873

Ellison AM, Dixon PM \& Ngai J (1994). A null model for neighborhood models of plant competitive interactions. Oikos 71:225-238

Eriksson O (1986). Mobility and space capture in the stoloniferous plant Potentilla anserina. Oikos 46:82-87

Evans JP (1991). The effect of resource integration on fitness related traits in a clonal dune perennial, Hydrocotyle bonariensis. Oecologia 86:268-275

Evans JP (1992). The effect of local resource availability and clonal integration on ramet functional morphology in Hytrocotyle bonariensis. Oecologia 89:265276

Fitter AH (1986). Acquisition and utilization of resources. In Plant Ecology, ed. Crawley MJ, pp. 375-405. Oxford, UK: Blackwell

Fitter AH \& Stickland TR (1991). Architectural analysis of plant root systems. II. Influence of nutrient supply on architecture in contrasting plant species. New Phytologist 118:383-389

Fitter AH, Stickland TR, Harvey ML \& Wilson GW (1991). Architectural analysis of plant root systems. I. Architectural correlates of exploitation efficiency. New Phytologist 118:375-382

Franco M (1986). The influence of neighbors on the growth of modular organisms with an example from trees. Proceedings of the Royal Society of London B 313:209-225

Franco M \& Harper JL (1988). Competition and the formation of spatial pattern in spacing gradients: An example using Kochia scoparia. Journal of Ecology 76:959-674

Franco Pizana JG, Fulbright TE, Gardiner DT \& Tipton AR (1996). Shrub emergence and seedling growth in microenvironments created by Prosopis glandulosa. Journal of Vegetation Science 7:257-264

Goldberg DE (1987). Neighborhood competition in an old-field plant community. Ecology 68:1211-1223

Goldberg DE (1990). Components of resource competition in plant communities. In Perspectives on Plant Competition, eds. Grace JB \& Tilman D, pp. 27-47. New York, NY, USA: Academic Press

Goldberg DE \& Barton AM (1992). Patterns and consequences of interspecific competition in natural communities: A review of field experiments with plants. The American Naturalist 139:771-801 
Goldberg DE \& Werner PA (1983). Equivalence of competitors in plant communities: A null hypothesis and a field experimental approach. American Journal of Botany 70:1098-1104

Grimm V (1994). Mathematical models and understanding in ecology. Ecological Modelling 75/76:641-651

Gurevitch J, Morrow LL, Wallace A \& Walsh JS (1992). Meta analysis of field experiments. The American Naturalist 140:539-572

Hara T, Wyszomirski T (1994). Competitive asymmetry reduces spatial effects on size-structure dynamics in plant populations. Annals of Botany 73:285-297

Harper JL (1977). Population Biology of Plants. London, UK: Academic Press

Hook PB \& Lauenroth WK (1994). Root system response of a perennial bunchgrass to neighborhood-scale soil water heterogeneity. Functional Ecology 8:738-745

Huber-Sannwald E, Pyke DA \& Caldwell MM (1996). Morphological plasticity following species-specific recognition and competition in two perennial grasses. American Journal of Botany 83:919-931

Huston MA \& DeAngelis DL (1994). Competition and coexistence: The effects of resource transport and supply rates. The American Naturalist 144:954-977

Hutchings MJ (1986). The structure of plant populations. In Plant Ecology, ed. Crawley MJ, pp. 97-136. Oxford, UK: Blackwell

Hutchings MJ (1988). Differential foraging for resources and structural plasticity in plants. Trends in Ecology and Evolution 3:200-204

Hutchings MJ \& de Kroon H (1994). Foraging in plants: The role of morphological plasticity in resource acquisition. In Advances in Ecological Research, Vol. 25, eds. Begon M \& Fitter AH, pp. 159-238. London, UK: Academic Press

Janzen DH (1970). Herbivores and the number of tree species in tropical forests. The American Naturalist 104:501-529

Jones M (1985). Modular demography and form in silver birch. In Studies on Plant Demography: A Festschrift for John L. Harper, ed. White J, pp. 223237. London, UK: Academic Press

Jones M \& Harper JL (1987a). The influence of neighbors on the growth of trees. I. The demography of buds in Betula pendula. Proceedings of the Royal Society of London B 232:1-18

Jones M \& Harper JL (1987b). The influence of neighbors on the growth of trees. II. The fate of buds on long and short shoots in Betula pendula. Proceedings of the Royal of Society London B 232:19-33

Keddy P (1991). Plant competition and resources in oldfields. Trends in Ecology and Evolution 6:235-237

Keddy PA \& Shipley B (1989). Competitive hierarchies in herbaceous plant communities. Oikos 54:234-241

Krannitz PG \& Caldwell MM (1995). Root growth responses of three Great Basin perennials to intra- and interspecific contact with other roots. Flora 190:161167 
Küppers M (1994). Canopy gaps: Competitive light interception and economic space filling - A matter of whole plant allocation. In Exploitation of Environmental Heterogeneity by Plants, eds. Caldwell MM \& Pearcy RW, pp. 111144. San Diego, CA, USA: Academic Press

Leadley PW, Reynolds JF \& Chapin FS (1997). A model of nitrogen uptake by Eriophorum vaginatum roots in the field: Ecological implications. Ecological Monographs 67:1-22

Lechowicz MJ \& Bell G (1991). The ecology and genetics of fitness in forest plants. II. Microspatial heterogeneity of the edaphic environment. Journal of Ecology 79:687-696

Mahall BE \& Callaway RM (1992). Root communication mechanisms and intracommunity distributions of two Mojave Desert shrubs. Ecology 73:2145-2151

Maillette L (1982a). Structural dynamics of Silver birch. I. The fate of buds. Journal of Applied Ecology 19:203-218

Maillette L (1982b). Structural dynamics of Silver birch. II. A matrix model of the bud population. Journal of Applied Ecology 19:219-238

Mitchell-Olds T (1987). Analysis of local variation in plant size. Ecology 68:8287

Novoplansky A, Cohen D \& Sachs T (1989). Ecological implications of correlative inhibition between plant shoots. Physiologia Plantarum 77:136-140

Pacala SW (1986). Neighborhood models of plant population dynamics. II. Multispecies models of annuals. Theoretical Population Biology 29:262-292

Pacala SW (1987). Neighborhood models of plant population dynamics. III. Models with spatial heterogeneity in the physical environment. Theoretical Population Biology 31:359-392

Pacala SW \& Deutschman D (1995). Details that matter: The spatial distribution of individual trees maintains forest ecosystem function. Oikos 74:357-365

Pacala SW \& Silander JA Jr (1985). Neighborhood models of plant population dynamics. I. Single-species models of annuals. The American Naturalist 125:385-411

Pacala SW \& Silander JA Jr (1987). Neighborhood interference among velvet leaf, Abutilon theophrasti, and pigweed, Amaranthus retroflexus. Oikos 48:217-224

Pacala SW \& Silander JA Jr (1990). Field tests of neighborhood population dynamic models of two annual weed species. Ecological Monographs 60:113134

Pacala SW, Canham CD, Saponara J, Silander JA Jr, Kobe RK \& Ribbens E (1996). Forest models defined by field measurements: Estimation, error analysis and dynamics. Ecological Monographs 66:1-43

Parrish JAD \& Bazzaz FA (1976). Underground niche separation in successional plants. Ecology 57:1281-1288

Parrish JAD \& Bazzaz FA (1985). Ontogenetic niche shifts in old-field annuals. Ecology 66:1296-1302

Pickett STA \& White PS (1985). The Ecology of Natural Disturbance and Patch Dynamics. New York, NY, USA: Academic Press 
Rice EL (1984). Allelopathy, 2nd edn. Orlando, FL, USA: Academic Press

Ricklefs RE \& Schluter D (1993). Species Diversity: Historical and Geographical Patterns. Chicago, IL, USA: University of Chicago Press

Schmid B (1990) Some ecological and evolutionary consequences of modular organization and clonal growth in plants. Evolutionary Trends in Plants 4:25-34

Schmitt J (1993). Reaction norms of morphological and life-history traits to light availability in Impatiens capensis. Evolution 47:1654-1668

Schmitt J \& Wulff RD (1993). Light spectral quality, phytochrome and plant competition. Trends in Ecology and Evolution 8:47-51

Silander JA Jr \& Pacala SW (1985). Neighborhood predictors of plant performance. Oecologia 66:256-263

Silvertown J \& Lovett Doust J (1993). Introduction to Plant Population Biology, 3rd edn. Oxford, UK: Blackwell

Slade AJ \& Hutchings MJ (1987a). The effects of nutrient availability on foraging in the clonal herb Glechoma hederacea. Journal of Ecology 75:95-112

Slade AJ \& Hutchings MJ (1987b). The effects of light intensity on foraging in the clonal herb Glechoma hederacea. Journal of Ecology 75:639-650

Sorrensen-Cothern KA, Ford ED \& Sprugel DG (1993). A model of competition incorporating plasticity through modular foliage and crown development. Ecological Monographs 63:277-304

Sprugel DG, Hinckley TM \& Schaap W (1991). The theory and practice of branch autonomy. Annual Review of Ecology and Systematics 22:309-334

Stoll P \& Schmid B (1998). Plant foraging and dynamic competition between branches of Pinus sylvestris in contrasting light environments. Journal of Ecology 86:934-945

Stoll P, Weiner J \& Schmid B (1994). Growth variation in a naturally established population of Pinus sylvestris. Ecology 75:660-670

Stuefer JF (1995). Separating the effects of assimilate and water integration in clonal fragments by the use of steam-girdling. Abstracta Botanica 19:75-81

Stuefer JF, During HJ \& deKroon H (1994). High benefits of clonal integration in two stoloniferous species, in response to heterogeneous light environments. Journal of Ecology 82:511-518

Sutherland WJ \& Stillman RA (1988). The foraging tactics of plants. Oikos 52:239-244

Thomas SC \& Weiner J (1989). Including competitive asymmetry in measures of local interference in plant populations. Oecologia 80:349-355

Tilman D (1982). Resource Competition and Community Structure. Princeton, NJ, USA: Princeton University Press

Tilman D (1988). Plant Strategies and the Dynamics and Structure of Plant Communities. Princeton, NJ, USA: Princeton University Press

Tilman D (1997). Community invasibility, recruitment limitation and grassland biodiversity. Ecology 78:81-92

Tremmel DC \& Bazzaz FA (1993). How neighbor canopy architecture affects target plant performance. Ecology 74:2114-2124 
Tyler CM \& D'Antonio CM (1995). The effects of neighbors on the growth and survival of shrub seedlings following fire. Oecologia 102:255-264

Vandermeer J (1984). Plant competition and the yield-density relationship. Journal of Theoretical Biology 109:393-399

Watkinson AR (1980). Density-dependence in single-species populations of plants. Journal of Theoretical Biology 83:345-357

Weiner J (1984). Neighborhood interference amongst Pinus rigida individuals. Journal of Ecology 72:183-195

Weiner J (1995). On the practice of ecology. Journal of Ecology 83:153-158 